Gazi University
Journal of Science
http://dergipark.gov.tr/gujs

\title{
External Heating of a Circular Annulus Cavity filled with Nano Fluid
}

\author{
Amar Hasan HAMEED* \\ KTO Karatay University, Mechanical Engineering Department, Akabe Mah., Alaaddin Kap Cd. No:130, 42020, Konya, Turkey
}

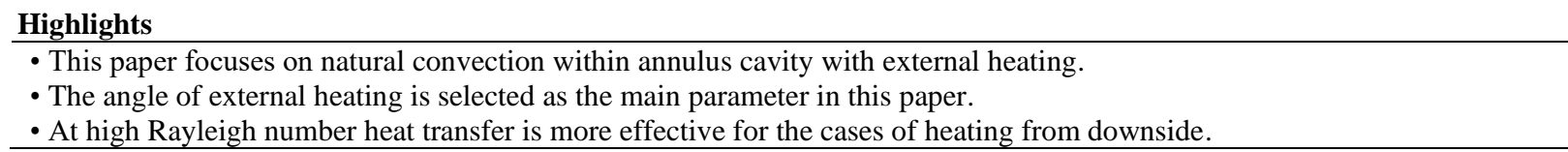

\section{Article Info}

Received: 12 Dec 2020

Accepted: 21 Nov 2021

\section{Keywords}

Annulus cavity

Natural convection

Thermal solar collector

Nano-fluid

Rayleigh number

\begin{abstract}
Nowadays, progress in direct absorption solar collectors requires further investigations to realize heat transfer occurring in a horizontal annulus cavity exposed to external heat from different angles. An annulus cavity filled with nano-fluid is numerically simulated by using Ansys-Fluent for Rayleigh number equals $10^{5}$. The external wall of two-dimensional model for the cavity is equally divided into six parts to simulate heating from isothermal walls placed in different angles. The internal wall has constant low temperature simulating a pipe conveys cold fluid and acting as heat sink. Hot isothermal walls set in different angles to simulate several heating cases according to hot element position. "Upper", "lower", "upper-right", "lower-right", "upper \& upper-right", "lower \& lower-right", "lower-right \& upper-right", "upper-half", and "lower-half" are the cases investigated to assess heating effectiveness for all possible directions of heating. It is found that heating in "lower" and "lower-right" cases is about six time that of "upper" case. In addition, heating improves slightly in the case of "lower-right" compared with that of "lower" heating. Heating effectiveness from two or three parts in the upper side appears less than heating of two or three parts from the lower side. Enlarging heating area not always reflects multiplication of heat transfer amount, natural convection on the cold wall decreases significantly due to restricted or weakened stream of fluid motion near to cold wall in poor heating cases. In conclusion, choosing correct direction of heating in annulus cavity demonstrates effective heating compared to that earned by enlarging heating area.
\end{abstract}

\section{INTRODUCTION}

The energy saving, transmitting, and generating become pivotal subject of all engineers and scientists in last several decades. In several industrial applications, natural convection of nano-fluid occurs in horizontal annulus cavity with different thermal boundary conditions such as the design of solar energy collectors, cooling of electric power cables, heat exchanger devices, nuclear and chemical reactors, food processing devices, etc. Nano-fluid participate in development of last versions of solar thermal collectors since it has enhanced thermal conductivity and high absorption factor. However, solar thermal collector does not contribute directly to the generation of clear electric energy, but it reduces the need of production of electric energy by using fossil fuel. So, investigations of heat transfer in solar thermal collector still have priority and significance in research. In addition, annulus configuration filled with nano-fluid and subjected to heat transfer also got the interest of many researchers who have investigated problems for different shapes, boundary conditions, and methods of solution. A lot of researchers examined natural convection in an annulus cavity with internal hot isothermal wall and external cold isothermal wall. Heat convection investigated for a range of Rayleigh number and different volume fractions for nano-fluid [1]. The noncircular geometry of the internal pipe (rather than circular like square, elliptical, triangular, and hexagonal) attracts the attention also and many investigations have been done on different shapes of the internal pipe rather than circular shape $[2,3]$. In addition, several boundary conditions for annular spaces have been 
conducted such as partial heated internal duct [4]. The influence of different geometry parameters such as aspect ratio and radius ratio on heat transfer in a vertical annulus cavity filled by water is studied by [5]. Inclination effect is studied as well, they found that Nusselt number increases linearly with radius ratio, it decreases (power low) with aspect ratio and increases (power low) with inclination angle. Natural convection within a square U-shaped enclosure contains nano-fluid and a cold rib is studied by [6]. They have studied heat transfer for different Rayleigh numbers and nanofluid volume fractions associated with range of two aspect ratios for the rib height and width to enclosure dimension. They have produced a correlation relating Nusselt number with Rayleigh number, volume fraction, and the two aspect ratios. Numerical simulation for mixed convection in an annulus formed between outer cold rotating cylinder and inner hot stationary cylinder and filled by hybrid nanofluid, is studied by [7]. They have studied the problem for different volume fractions, angular velocities, Rayleigh numbers, and eccentricity of inner cylinder. They found that heat transfer enhances by increasing volume fraction, eccentricity, Rayleigh number, and reduction of angular velocity. The influence of inner hot cylinder boundary condition and aspect ratio have been studied by [8], and the influence of inner hot cylinder shape on heat transfer is studied by [9]. Nusselt number increases by increasing aspect ratio, angle of heat flux from the positive y-axis, sharp corners, and by the increasing the space area in the top of elliptical annulus compared with that of cylindrical one.

Using Nano-fluid in solar thermal collector raises many questions about heat transfer process within different configurations of solar collectors. In some designs of solar collectors, nano-fluid circulates between solar collector and heat exchanger to exchange heat to water which needs heating. In the mentioned model, active heat transfer technique is used inside the collector and heat transfers by forced convection. Passive heat technique also used in other models which depends on heat transfer by natural convection. A new configuration of solar thermal collector has been suggested recently. It includes natural convection within annulus of concentric two cylinders filled with nano-fluid and forced convection within water flows inside internal pipe [10]. In direct absorption solar collectors, nano-fluid absorbs solar radiation passes through a transparent wall, while opaque walls in indirect absorption solar collector absorbs heat and transmits it to either heated fluid or to a medium fluid consists of nano-fluid. Heat transfer occurs in different ways in solar thermal collectors, heat conducts through opaque walls sometimes or generated within the fluid by absorption of solar radiation sometimes. Heat fluxes incidents in different angles on the surface of collector. In concentrated collectors, radiation incidents from different angles downside collector tubes when a reflector is used, while in non-concentrated collectors radiation incidents from different angles during different times of day. Thermal solar collectors consist of copper tubes or glass tubes or a combination of copper tube and glass tube forming concentric annulus [10]. Principally, natural convection within a heated fluid works more effectively when source of heating position locates downside the space filled by the fluid, however using nano-fluid, which has high thermal conductivity, may reduce the importance of the position of heating of fluid. The position of heat source and its' direction of incidence may play an important role for concentrated solar collectors and non-concentrated. This concern grows during the study of different designs of solar collectors when they receive incident radiation from different incidence angles and with various intensities. Heat transfer occurs during heating by a source located partially at an external wall of an annulus cavity bordered by inner surface works as a thermal sink. This work investigates natural convection flow patterns and temperature distribution within an annulus cavity formed by two concentric cylinders considering heated part of the external wall located in different angles according to the annulus axis.

\section{MATERIAL METHOD}

\subsection{Problem Description}

A two-dimensional model of two concentric cylinders was prepared to simulate the cavity in a horizontal tube. Since the tube is horizontal, it is assumed that there is no significant change in the flow and heat transfer in $\mathrm{z}$-direction. Nano-fluid exists between two concentric cylinders with radii ratio of $\mathrm{R}_{\mathrm{ou}} / \mathrm{R}_{\mathrm{in}}=2.0$. The inner cycle represents cold wall with isothermal wall boundary condition $T_{c}$. The external cycle is divided into six equal parts, as shown in Figure 1. Every part is named regarding to its position as follows; upper, upper right, upper left, lower, lower right, and lower left. Cases of constant temperature wall boundary conditions are assumed by selecting one or two or three of these walls as hot walls $\left(T_{h}\right)$ and the 
remaining as adiabatic walls. The cavity is filled with nano-fluid consists of oil and copper dioxide. The mixture is assumed to be homogeneous and has constant thermophysical properties except for density property which varies according to Boussinesq approximation. The radiation affect between the internal and external walls and dissipation heating effect also are neglected in the model. The flow is laminar and steady within the cavity. The fluid is a stable homogeneous mixture of base fluid and nano particles, it is assumed as continuous media, Newtonian, and incompressible. The thermophysical properties of base fluid [11] and nanoparticles [12] used are listed in Table 1. Heating boundary conditions are selected to cover all the available probabilities; one part, two parts, and three parts heating. This provides wide range of applicable cases with various areas and positions.

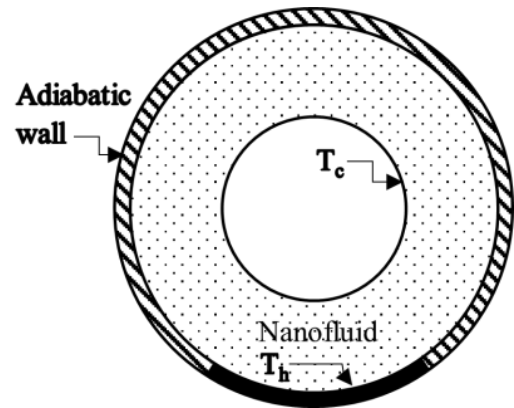

(a)

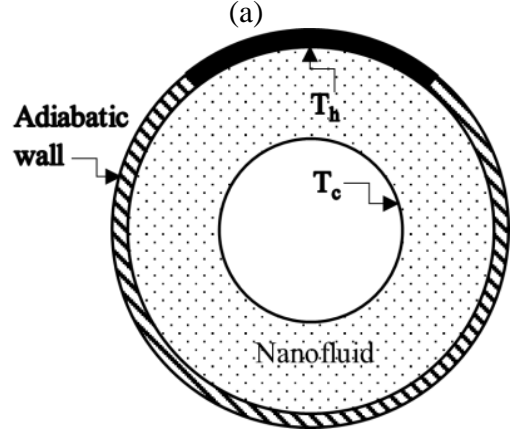

(d)

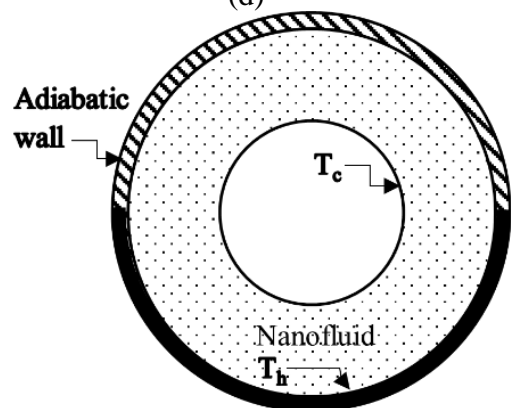

(g)

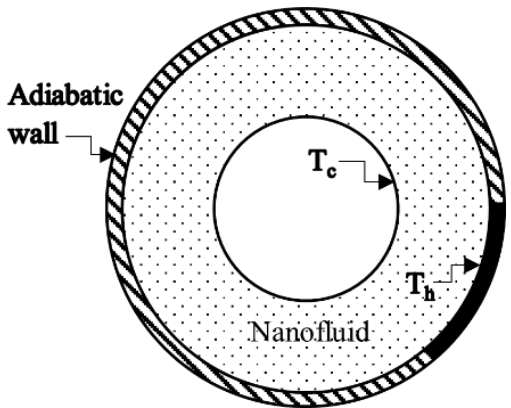

(b)

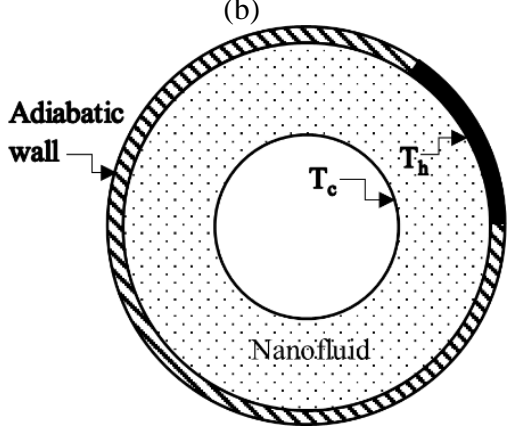

(e)

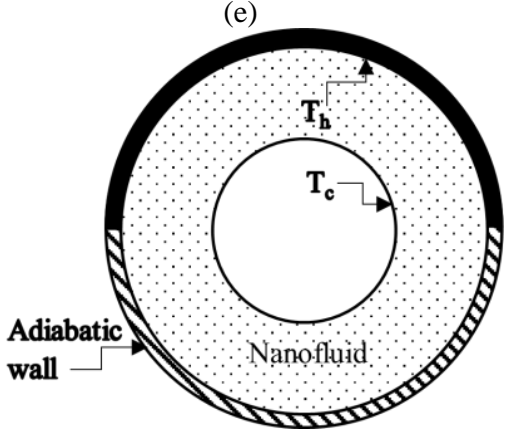

(h)

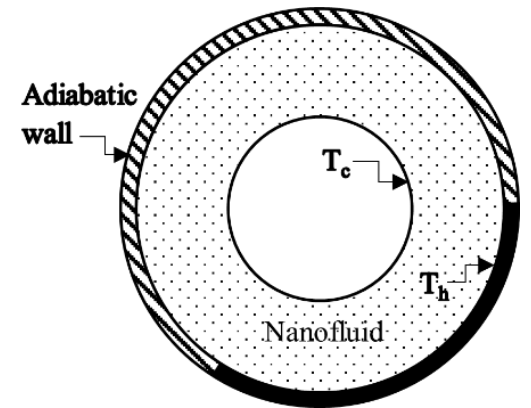

(c)

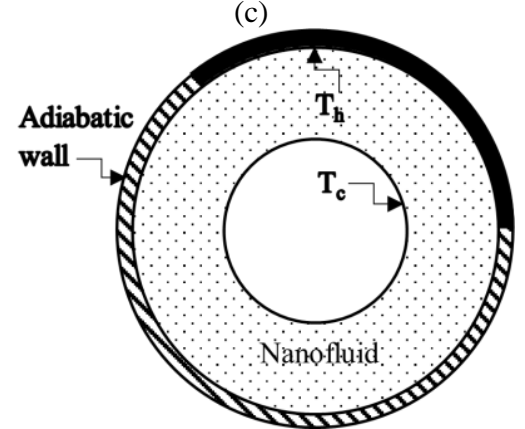

(f)

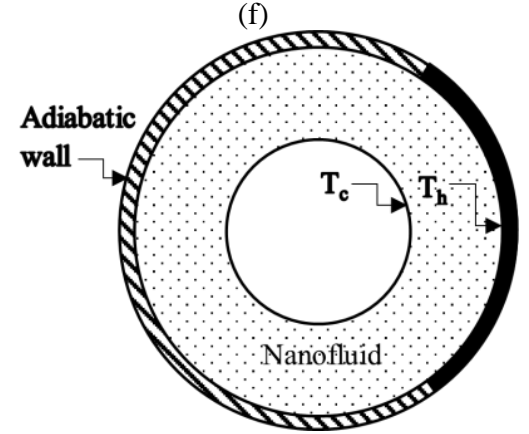

(i)

Figure 1. Schematic and boundary conditions of a) Lower case b) Lower right c) Lower right \& Lower d) Upper case e) Upper rightf) Upper right \& Upper g) Lower half h) Upper half i) Lower right \& Upper right

Table 1. Thermophysical properties of oil and nanoparticles

\begin{tabular}{|l|l|l|l|l|l|}
\hline & $\rho$ & $\mathrm{C}_{\mathrm{p}}$ & $K$ & $\mu$ & $\beta$ \\
& $\mathrm{Kg} \cdot \mathrm{m}^{-3}$ & $\mathrm{~J} .(\mathrm{kg} \cdot \mathrm{k})^{-1}$ & $\mathrm{~W} \cdot \mathrm{m}^{-1} \cdot \mathrm{K}^{-1}$ & $\begin{array}{l}\mu \text { Pa.s } \\
\mathrm{K}^{-1}\end{array}$ \\
\hline Oil $(5 \mathrm{w} 30)$ & 840 & 1900 & 0.14 & 0.063 & $70 \times 10^{-5}$ \\
\hline $\mathrm{CuO}$ & 6300 & 475 & 33 & - & $1.8 \times 10^{-5}$ \\
\hline
\end{tabular}




\subsection{Governing Equations}

The equations of 2D steady laminar flow used to find the solution of this problem are listed below:

Continuity equation:

$\frac{\partial U}{\partial x}+\frac{\partial V}{\partial y}=0$

Momentum equations:

$U \frac{\partial U}{\partial x}+V \frac{\partial U}{\partial y}=\frac{-1}{\rho_{n f}} \frac{\partial P}{\partial x}+v_{n f}\left(\frac{\partial^{2} U}{\partial x^{2}}+\frac{\partial^{2} U}{\partial y^{2}}\right)$

$U \frac{\partial V}{\partial x}+V \frac{\partial V}{\partial y}=\frac{-1}{\rho_{n f}} \frac{\partial P}{\partial y}+\frac{(\rho \beta)_{n f}}{\rho_{n f}}\left(T-T_{C}\right)+v_{n f}\left(\frac{\partial^{2} V}{\partial x^{2}}+\frac{\partial^{2} V}{\partial y^{2}}\right)$

Energy equation:

$U \frac{\partial T}{\partial x}+V \frac{\partial T}{\partial y}=(\alpha)_{n f}\left(\frac{\partial^{2} T}{\partial x^{2}}+\frac{\partial^{2} T}{\partial y^{2}}\right)$

Density and specific heat of nano-fluid is function of volume fraction $\varphi$ and the properties of base fluid and nanoparticles [1]:

$(\rho)_{n f}=\varphi \rho_{p}+(1-\varphi) \rho_{f}$

$\left(\rho C_{p}\right)_{n f}=\varphi\left(\rho C_{p}\right)_{p}+(1-\varphi)\left(\rho C_{p}\right)_{f}$

where $\left(\rho_{\mathrm{nf}}\right)$ is the density of nano-fluid, $\left(\rho_{\mathrm{f}}\right)$ is the density of base fluid, $\left(\rho_{\mathrm{p}}\right)$ is the density of the nanoparticles, $\varphi$ is the volume fraction of the $\mathrm{CuO}$ nanoparticles, $(\mathrm{Cp})_{\mathrm{nf}}$ is the specific heat of nano-fluid, $(\mathrm{Cp})_{f}$ is the specific heat of base fluid, $(\mathrm{Cp})_{p}$ is the specific heat of $\mathrm{CuO}$ nanoparticles. The effective dynamic viscosity for nano-fluid can be calculated from the following equation

$\mu_{n f}=\left(1+2.5 \varphi+6.2 \varphi^{2}\right) \mu_{f}$

where $\left(\mu_{n f}\right)$ is the dynamic viscosity of suspension, $\left(\mu_{f}\right)$ is the viscosity of base fluid. The thermal expansion coefficient of the nanofluid can be determined by:

$(\rho \beta)_{n f}=\varphi(\rho \beta)_{p}+(1-\varphi)(\rho \beta)_{f}$

The effective thermal conductivity of the nanofluid, which is for low dense mixtures with micro-sized spherical particles, according to Maxwell, is:

$K_{n f}=K_{f} \frac{\left(K_{p}+2 K_{f}\right)-2 \varphi\left(K_{f}-K_{p}\right)}{\left(K_{p}+2 K_{f}\right)+\varphi\left(K_{f}-K_{p}\right)}$

where $\left(\mathrm{k}_{p}\right)$ is the thermal conductivity of the nanoparticles, $\left(\mathrm{k}_{n f}\right)$ is the thermal conductivity of nano-fluid, $\left(\mathrm{k}_{f}\right)$ is the base fluid thermal conductivity. Thermal diffusivity of the nanofluid is: 


$$
(\alpha)_{n f}=\frac{K_{n f}}{(\rho C p)_{n f}} .
$$

The dimensionless number associated with buoyancy driven flow is useful to characterize the nature of flow. It is calculated according to the following equation [13]

$$
R a=\frac{g \beta_{n f}\left(R_{2}-R_{1}\right)^{3}\left(T_{H}-T_{C}\right)}{v_{n f} \alpha_{n f}}
$$

\subsection{Numerical Model}

The numerical model is generated by using ANSYS-FLUENT software. The annulus field is subdivided into number of quadrilateral cells when the finer mesh allocates near walls, while coarser grids cover the remaining area. Three different mesh schemes are tested to guarantee a grid independent solution. Heat transfer coefficient on the cold surface and hot surface represents the best criteria suitable to perform this test. Heat transfer coefficient is calculated for every surface from the facet average or by the area-weighted average of heat transfer throughout all the cells on the surface in the numerical model. The case of lower right is selected for the test of grid independence because it shows dramatic changes in temperature and velocity. In Table 2, the results of heat transfer coefficient on both hot and cold surfaces are listed against low, medium, and high number of cells. The difference between results of two sequent cases is taken as the base of absolute error mentioned in the table. The absolute error between high mesh and medium mesh drops less than $0.6 \%$ for both hot wall and cold wall. So, this demonstrates the case of unnecessity of high number of mesh, whereas low mesh number is insufficient for accurate results. As a result, the mesh of cells' number of $\left(7.54 \times 10^{3}\right)$ is used in the numerical model for all remaining cases. The energy equation is validated in the model by the balance of heat sourcing and sinking through the boundaries of the model. Then, the model is validated by comparison of the results of current model under same conditions with other models in the literature. For Rayleigh number equals $4.7 \times 10^{4}$ and zero angle starts at the negative $y$ axis, the results of dimensionless temperature against dimensionless distance are found along horizontal line $\left(90^{\circ}\right)$ and vertical line $\left(0^{\circ}\right)$. The results are compared with the available numerical results predicted by $[3,13]$ and experimental results of Kuehn cited by [13] as shown in Figure 2. The comparisons show excellent agreement between results of the current model and results of the literatures.

\begin{tabular}{|c|c|c|c|c|}
\hline No. of cells & $\begin{array}{l}\mathrm{h}\left(\mathrm{W} / \mathrm{m}^{2} . \mathrm{K}\right) \text {, } \\
\text { for hot wall }\end{array}$ & |Error| & $\begin{array}{l}\mathrm{h}\left(\mathrm{W} / \mathrm{m}^{2} . \mathrm{K}\right) \text {, } \\
\text { for cold wall }\end{array}$ & |Error| \\
\hline $3.24 \times 10^{3}$ & 65.03 & \multirow{2}{*}{$1.3 \%$} & 109.02 & \multirow{2}{*}{$2.43 \%$} \\
\hline $7.54 \times 10^{3}$ & 64.14 & & 111.68 & \\
\hline $11.46 \times 10^{3}$ & 63.76 & $0.59 \%$ & 111.02 & $0.59 \%$ \\
\hline
\end{tabular}

Table 2. No. of cells versus heat transfer coefficient on hot and cold walls 


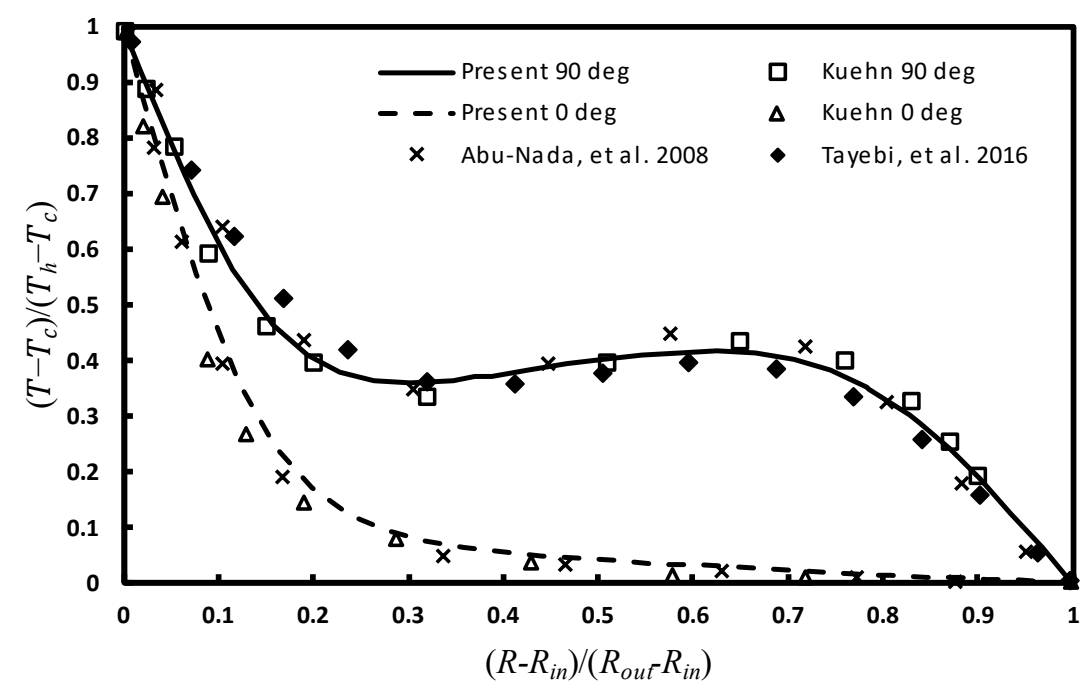

Figure 2. Validation of the numerical model by comparing with numerical and experimental results in the literature [3, 13]

\section{THE RESEARCH FINDINGS AND DISCUSSION}

By the definition of Rayleigh number, effect of natural convection for low Rayleigh number is limited and heat transfer by conduction is dominant. So, high value of Rayleigh number is selected to ensure that natural convection will be the dominant. Rayleigh number equal 105 value is selected for all cases. Since there is axisymmetric in this problem, the cases in the right side enough to express same results for the left side because of symmetrical geometry. Table 3 shows the results of using different cases of heating by switching the position of hot wall and the number of heated walls in addition to Nusselt number for hot and cold surfaces. Normalized heating amount is taken when the amount of heating in every case divided by the amount of heating of one part in the lower side (case (a)) which equal $100.62 \mathrm{~W}$ and taken as a reference. The role of natural convection over thermal conduction is very significant, when heating ratio drops to approximately one-sixth for the case of upper heating in case (d) compared with case (a). Little bit improvement in case (b) appears over case (a) when heating is shifted left or right in the lower half. Side heating in case (i), two parts are heated together (lower right \& upper right). Heat transfer from upper right in case (i) less than that of case (e) which is heated alone because, the stream of hot fluid coming from lower right part and flow over the upper-right will reduce effectivity of heat transfer from the upper right surface. Same thing happens in case (c) when lower surface and lower-right surface affect heating rate of each other when it is compared with case (a) and case (b). General look to the table proves that; heating is more effective when it is in the lower side of the cavity. In addition, using two-parts in the upper side in case (f) results in poor heating compared with one-part heating in case (a), however the area is doubled. Multiplication the area by three in upper side (case (h)) which means heating of the upper half reveals only $10 \%$ improvement of heating compared with the first case. The maximum amount of heating appears in case $(\mathrm{g})$ when the whole lower side is heated.

The results of Nusselt number on hot and cold surface also reveals important ideas in Table 3. Thermal resistance on the cold and hot surface depends on the direction of heating and angle of heating element in addition to the area of heating surface. For one part heating, maximum thermal resistance (minimum $\mathrm{Nu}$ ) at both hot and cold walls appears in the case of upper heating, while upper right heating shows improvements of Nusselt number on both surfaces by more than four times. On both cold and hot surfaces, minimum thermal resistance (maximum $\mathrm{Nu}$ ) appears in the case of lower and lower right for two parts heating, and lower half heating for three parts heating. In these two cases, the reason behind that is the regular distribution of temperature in the fluid around the cold surface as appear by the isotherms in Figure 3 (c) and (g). However, cold surface temperature is constant in all cases, Nusselt number on the cold surface varies accordingly as fluid temperature around the cold surface be higher by the appropriate heating by hot surface. So, Nusselt number on both surfaces proportional to each other. 
Table 3. Heating ratio, Nusselt no. for different cases of heating

\begin{tabular}{|c|c|c|c|c|c|c|c|}
\hline \multirow[b]{2}{*}{ Case name } & \multicolumn{5}{|c|}{ Heating ratio } & \multirow[b]{2}{*}{$\begin{array}{l}\mathrm{Nu} \text {, hot } \\
\text { surface }\end{array}$} & \multirow[b]{2}{*}{$\begin{array}{l}N u, \text { cold } \\
\text { surface }\end{array}$} \\
\hline & Lower & Upper & $\begin{array}{l}\text { Lower } \\
\text { right }\end{array}$ & $\begin{array}{l}\text { Upper } \\
\text { right }\end{array}$ & $\begin{array}{l}\text { Total } \\
\text { heating }\end{array}$ & & \\
\hline $\begin{array}{l}\text { (a) } \\
\text { One-part }\end{array}$ & 1.00 & & & & 1.00 & 11.50 & 18.87 \\
\hline $\begin{array}{l}\text { (b) } \\
\text { One-part }\end{array}$ & & & 1.03 & & 1.03 & 11.95 & 19.88 \\
\hline $\begin{array}{l}\text { (c) } \\
\text { Two-parts }\end{array}$ & 0.885 & & 0.63 & & 1.51 & 17.57 & 29.24 \\
\hline $\begin{array}{l}\text { (d) } \\
\text { One-part }\end{array}$ & & 0.17 & & & 0.17 & 2.02 & 3.36 \\
\hline $\begin{array}{l}\text { (e) } \\
\text { One-part }\end{array}$ & & & & 0.73 & 0.73 & 8.47 & 14.08 \\
\hline $\begin{array}{l}\text { (f) } \\
\text { Two-parts }\end{array}$ & & 0.09 & & 0.665 & 0.756 & 8.68 & 13.97 \\
\hline $\begin{array}{l}\text { (g) } \\
\text { Three-parts }\end{array}$ & 0.88 & & $\begin{array}{l}0.496 \\
\text { right \& } \\
\text { left }\end{array}$ & & 1.87 & 21.73 & 36.15 \\
\hline $\begin{array}{l}\text { (h) } \\
\text { Three-parts }\end{array}$ & & 0.02 & & $\begin{array}{l}0.54 \text { right } \\
\& \text { left }\end{array}$ & 1.10 & 12.77 & 21.23 \\
\hline $\begin{array}{l}\text { (i) } \\
\text { Two-parts }\end{array}$ & & & 1.00 & 0.35 & 1.35 & 15.66 & 26.05 \\
\hline
\end{tabular}

Isotherms of all these cases are shown in Figure 3. Due to the significance of natural convection, the three cases (a), (b), and (c) own the more homogeneous temperature distribution and higher rate of average temperatures compared with that of the cases (d), (e), and (f). The first three cases include heating from downside of the cavity, whereas the second three cases include heating cases from upper side of the cavity. The blue regions (cold region) dominant mainly in the second three cases, and the chance for mixing hot and cold liquid still limited and non-homogeneity of temperature distribution appears significantly. The difference between heating in upper half and lower half seems meaningfully in the isotherms of cases $(\mathrm{g})$ and (h), in addition to 11-degree difference in the average temperature. However, three parts heating occurs in (h) case, temperature distribution still restricted and appears only in the upper region, while the lower region still looks like none-heated region. Heating two parts from the lateral side in case (i) exposes more homogeneous isotherms compared with upper heating but, it is not in same degree of homogeneity shown in the lower heating of two parts in case (c) which also has higher average temperature.

Figure 4 shows the contours of stream function for all cases. When we have heating at top or bottom of the cavity there will be a chance to generate two or more than two separated vortices of flow. This appears clearly in cases; (a), (c), (d), (g), and (h). Although, we have exception in case (f) when heating in the upper part is weakened by the effect of heating from upper-right part as shown by values in case (f) listed in Table 3. For this reason, cases (e) and (f) look like having approximately the same profile of stream function. One vortex generates in other cases which have heating from lateral sides. Moreover, in lateral side heating in cases (b), (e), and (i), it appears that there is inequality in the distribution of flow. The liquid rotates in shorter way between the heated part and the internal cold wall and do not move in the region far from the heated part. This may be the reason behind the little shortage noticed in the lateral side heating. Because heat exchange on the internal cold wall restricts on partial of the area of the cold wall and it becomes nonsignificant on the part of wall far from the heated wall. On the other hand, case (b) has advantage on cases (e) and (i) and better heat transfer occurs, because the flow around the internal wall in the left side has thick flow and large distance between lines of stream functions appears in the figure 4 (b). Which results in improved heat transfer around the internal wall. In case (d) high drop in the isotherms in short distances creates chains of vortices between the hot and cold walls, so the thermal resistance due natural convection remain high and heat transfer keep poor. In case (h), despite heating three parts and we have two vortices, but they have limited contact area with cold wall. It looks like there in no natural convection in the lower 
half. In contrast with cases (a), (c), and (g), the two vortices in these cases cover the internal wall completely. So, they have the maximum heat transfer for one-part, two-parts, and three-parts heating, respectively. Lateral heating stimulates the flow and increases the value of maximum stream function as appear in the case (i), in other side, heating in lower part may create more than one vorticity of flow. Heating amount and effectivity depends on these two parameters (flow pattern and flow amount) to reduce thermal resistance on the external wall and the internal wall also. Stream function shows flow amount and path which important to describe all the physics occurs in natural convection.

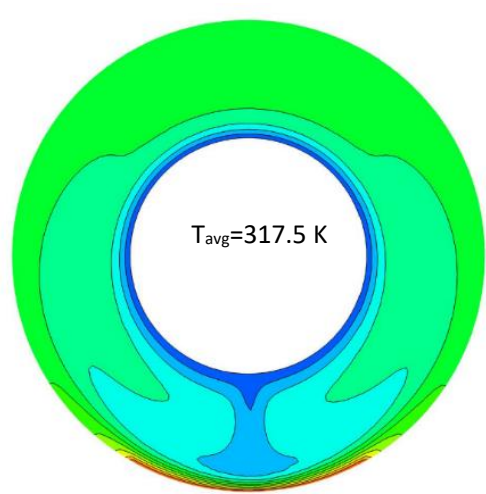

(a)

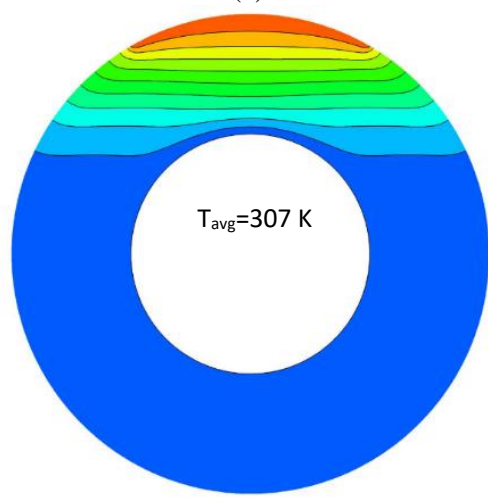

(d)

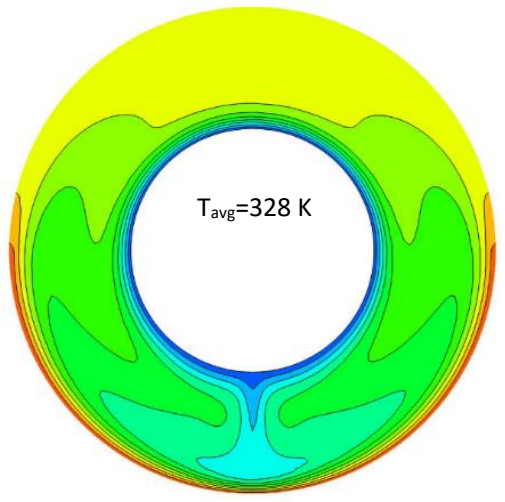

(g)

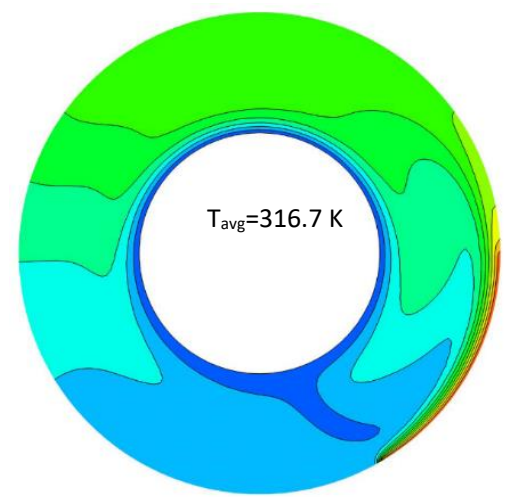

(b)

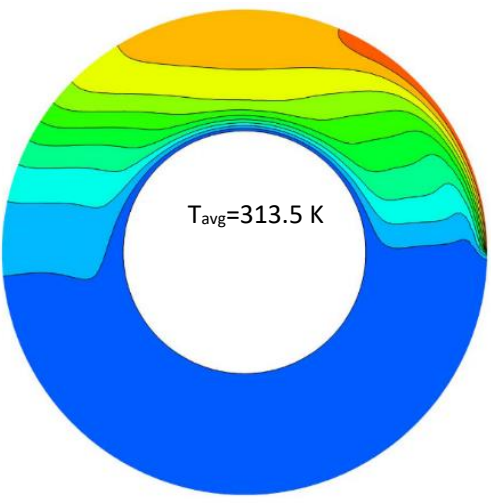

(e)

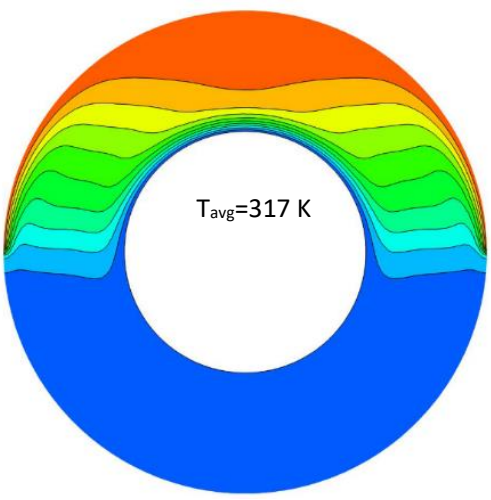

(h)

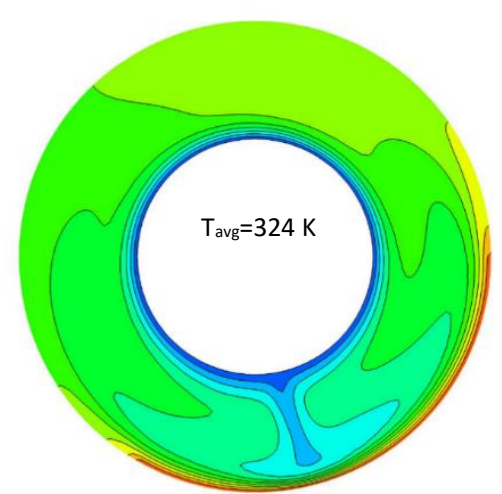

(c)

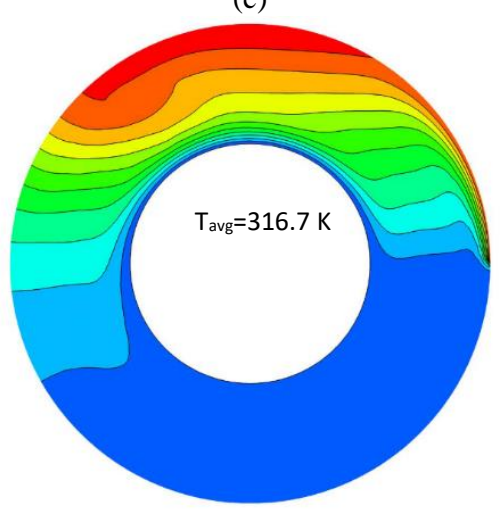

(f)

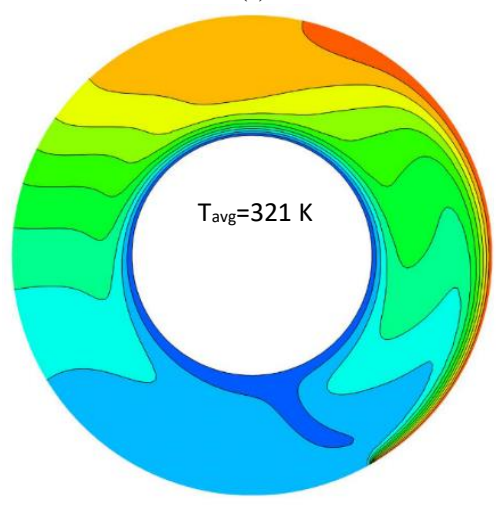

(i)

Figure 3. Isotherms of a) Lower case b) Lower right c) Lower right \& Lower d) Upper case e) Upper right f) Upper right \& Upper g) Lower half h) Upper half i) Lower right \& Upper right 


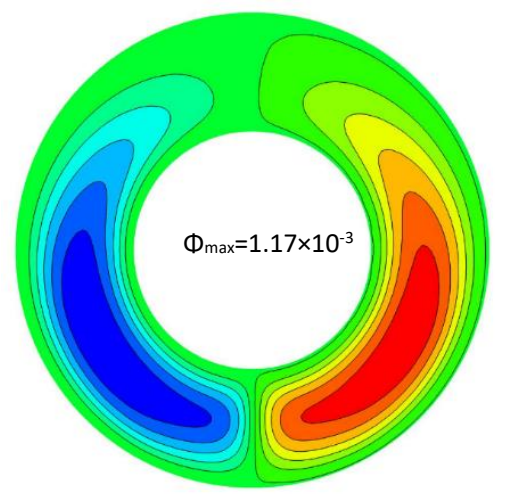

(a)

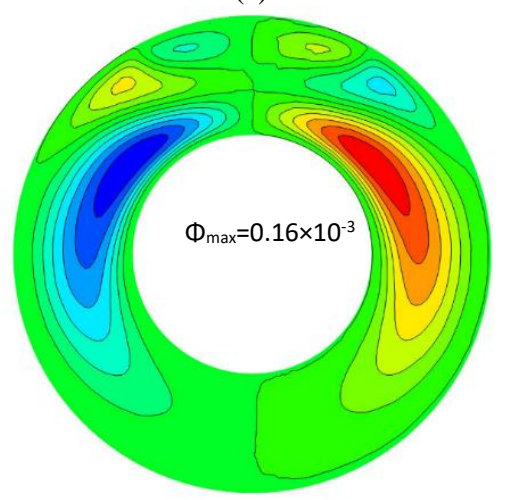

(d)

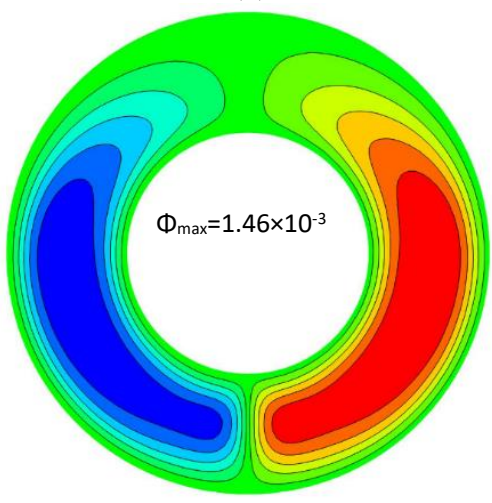

(g)

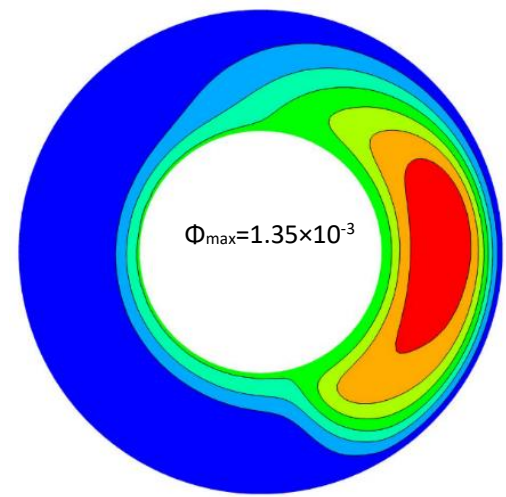

(b)

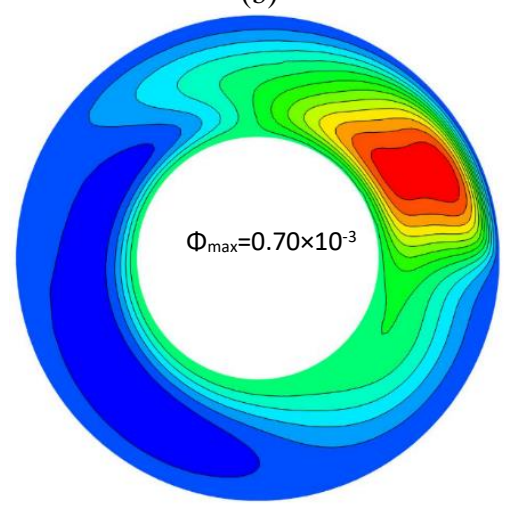

(e)

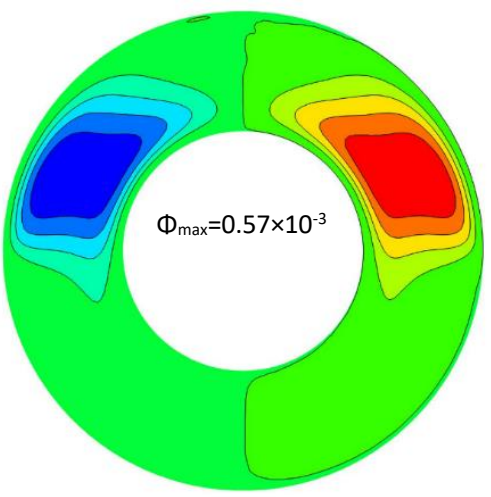

(h)

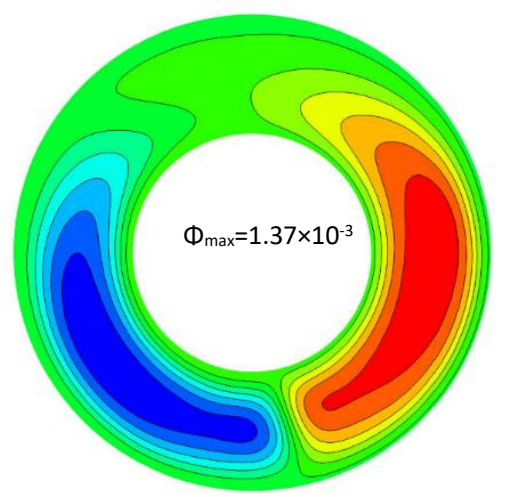

(c)

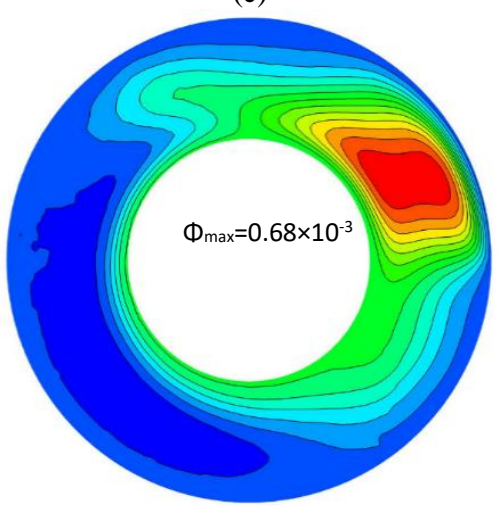

(f)

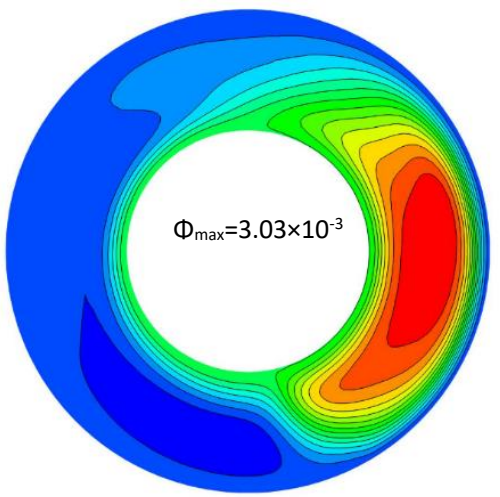

(i)

Figure 4. Stream functions contour of a) Lower case b) Right Lower c) Right Lower \& Lower d) Upper case e) Right upper f) Right Upper \& Upper g) Lower half h) Upper half i) Right lower \& Right Upper

\section{RESULTS}

Isotherms and stream function contours of nine cases of heating from different angles reveal a lot of ideas for heat transfer in a concentric circular cavity. For Rayleigh number equal $10^{5}$, natural convection is obviously significant and the difference between different angles of heating at the external wall expresses significant results. There are some important points can be written briefly,

- When hot surface locates downward, it shows higher rate of heat transfer compared with that of cases includes hot surfaces in the upper side.

- Temperature contours show that; homogeneous temperature distribution appears only for heating from down-side of the cavity, and in all cases include hot part in the upper side of the cavity shows ineffective heat transfer and large area of none-heated fluid.

- Duplicating of hot surface area doesn't result in duplication of heat transfer amount because the importance of hot surface location regarding cold fluid and regarding to the cold surface. 
- Generating two vortices of natural convection covering whole internal wall will improve heat transfer. Existing of single vortex in some cases results in restricted heat transfer to the internal wall unless this vortex surrounds the whole internal surface adequately.

- Nusselt number on cold surface proportionally related to that of hot surface, homogenous distribution of temperature in fluid reflects the best conditions for higher Nusselt number on the cold surface.

This study investigated heat transfer from outer surface to inner surface by natural convection in nano-fluid and showed the importance of the location of the heat source and its angle.

\section{CONFLICTS OF INTEREST}

No conflict of interest was declared by the author.

\section{NOMENCLUTER}

$\begin{array}{lll}C_{p} & {[\mathrm{~J} /(\mathrm{kg} . \mathrm{k})]} & \text { Specific heat } \\ g & {\left[\mathrm{~m} / \mathrm{s}^{2}\right]} & \text { Gravitational acceleration } \\ h & {\left[\mathrm{~W} / \mathrm{m}^{2} . \mathrm{K}\right]} & \text { Heat transfer coefficient } \\ K & {[\mathrm{~W} /(\mathrm{m} . \mathrm{K})]} & \text { Thermal conductivity } \\ L & {[\mathrm{~m}]} & \text { Characteristic length } \\ N u & {[--]} & \text { Nusselt number } \\ p & {\left[\mathrm{~N} / \mathrm{m}^{2}\right]} & \text { Pressure } \\ R & {[\mathrm{~m}]} & \text { Radius } \\ R e & {[--]} & \text { Reynolds number } \\ T & {[\mathrm{~K}]} & \text { Temperature } \\ U, V & {[\mathrm{~m} / \mathrm{s}]} & \text { Velocity in x and y direction }\end{array}$

$\begin{array}{ll}\text { Sub and superscripts } \\ \text { avg } & \text { Average } \\ c & \text { Cold } \\ f & \text { Base fluid } \\ h & \text { Hot } \\ \text { in } & \text { Internal circle } \\ \text { max } & \text { Maximum } \\ n f & \text { Nanofluid } \\ \text { out } & \text { External circle } \\ p & \text { Solid particle }\end{array}$

\begin{tabular}{lll}
\multicolumn{3}{l}{ Special characters } \\
$\alpha$ & {$\left[\mathrm{m}^{2} / \mathrm{s}\right]$} & Thermal diffusivity \\
$\beta$ & {$[1 / \mathrm{K}]$} & Thermal expansion coefficient \\
$\varphi$ & {$[--]$} & Volume fraction \\
$\Phi$ & {$[\mathrm{kg} / \mathrm{m} . \mathrm{s}]$} & Stream function \\
$\mu$ & {$[\mathrm{Pa} . \mathrm{s}]$} & Fluid viscosity \\
$\rho$ & {$\left[\mathrm{kg} / \mathrm{m}^{3}\right]$} & Gas density \\
$v$ & {$\left[\mathrm{~m}^{2} / \mathrm{s}\right]$} & Kinematic viscosity
\end{tabular}




\section{REFERENCES}

[1] Mihoubi, H., Bouderah, B., and Tayebi, T., "Improvement of free convection heat transfer in a concentric cylindrical annulus heat exchanger using nanofluid", Mathematical Modelling of Engineering Problems, 6(4): 566-574, (2019).

[2] Alapati, S., "Simulation of natural convection in a concentric hexagonal annulus using the lattice boltzmann method combined with the smoothed profile method", Mathematics, 8(6): 1043, (2020).

[3] Tayebi, T., Djezzar, M., Bouzerzour, A., Azzouz, K., and Khan, Z. H., "Numerical simulation of natural convection of water based nanofluids in horizontal eccentric cylindrical annuli", Journal of Nanofluids, 5(2): 253-263, (2016).

[4] Bouzerzour, A., Djezzar, M., Oztop, H.F., Tayebi, T., and Abu-Hamdeh, N., "Natural convection in nanofluid filled and partially heated annulus: Effect of different arrangements of heaters", Physica A: Statistical Mechanics and its Applications, 538: 122479, (2020).

[5] Husain, S., Siddiqui, M.A., and Khan, S.A., "Effect of geometrical parameters on natural convection of water in a narrow annulus", Progress in Nuclear Energy, 112(2019): 146-161, (2019).

[6] Yıldız, Ç., Arıcı, M., Karabay, H., and Bennacer, R., "Natural convection of nanofluid in a U-shaped enclosure emphasizing on the effect of cold rib dimensions", Journal of Thermal Analysis and Calorimetry, 146: 801-811, (2020).

[7] Selimefendigil, F., Oztop, H.F., and Ali, M. E., "Mixed Convection of Hybrid Nanofluids in an Annulus", Journal of Modeling and Optimization, 10(2): 55, (2018).

[8] Seyyedi, S.M., Dayyan, M., Soleimani, S., and Ghasemi, E., "Natural convection heat transfer under constant heat flux wall in a nanofluid filled annulus enclosure", Ain Shams Engineering Journal, 6(1): 267-280, (2015).

[9] Yuan, X., Tavakkoli, F., and Vafai, K., “Analysis of natural convection in horizontal concentric annuli of varying inner shape", Numerical Heat Transfer; Part A: Applications, 68(11): 1155-1174, (2015).

[10] Hameed, A. H., Nawaf, M. Y., "Direct Absorption Process in an Annular Space for Innovative Solar Collector", Advanced Science Letters, 24(11): 8957-8961, (2018).

[11] Silva, B.L.L.D., Souza, M.A.B.B., Medeiros, M.B.O., Rojas, E.E.G., and Castro, J.A., "Rheological study of Sae 5W30 Engine Oil and their emulsions", Proceedings of the 23rd ABCM International Congress of Mechanical Engineering, (March 2016)(2015).

[12] Xu, G., Chen, W., Deng, S., Zhang, X., and Zhao, S., "Performance evaluation of a nanofluid-based direct absorption solar collector with parabolic trough concentrator", Nanomaterials, 5(4): 21312147, (2015).

[13] Abu-Nada, E., Masoud, Z., and Hijazi, A., "Natural convection heat transfer enhancement in horizontal concentric annuli using nanofluids", International Communications in Heat and Mass Transfer, 35(5): 657-665, (2008). 